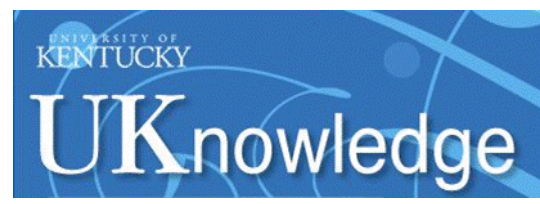

University of Kentucky

UKnowledge

3-27-2018

\title{
Modeling of NiTiHf Using Finite Difference Method
}

\author{
Nazanin Farjam \\ The University of Toledo \\ Reza Mehrabi \\ The University of Toledo \\ Haluk E. Karaca \\ University of Kentucky, karacahaluk@uky.edu \\ Reza Mirzaeifar \\ Virginia Tech \\ Mohammad Elahinia \\ The University of Toledo
}

Follow this and additional works at: https://uknowledge.uky.edu/me_facpub

Part of the Materials Science and Engineering Commons, and the Mechanical Engineering Commons Right click to open a feedback form in a new tab to let us know how this document benefits you.

\section{Repository Citation}

Farjam, Nazanin; Mehrabi, Reza; Karaca, Haluk E.; Mirzaeifar, Reza; and Elahinia, Mohammad, "Modeling of NiTiHf Using Finite Difference Method" (2018). Mechanical Engineering Faculty Publications. 51. https://uknowledge.uky.edu/me_facpub/51

This Conference Proceeding is brought to you for free and open access by the Mechanical Engineering at UKnowledge. It has been accepted for inclusion in Mechanical Engineering Faculty Publications by an authorized administrator of UKnowledge. For more information, please contact UKnowledge@lsv.uky.edu. 


\section{Modeling of NiTiHf Using Finite Difference Method}

\section{Digital Object Identifier (DOI)}

https://doi.org/10.1117/12.2300857

\section{Notes/Citation Information}

Published in Proceedings of SPIE, v. 10596, Behavior and Mechanics of Multifunctional Materials and Composites XII, article 1059613, p. 1-6.

(C) 2018 SPIE. One print or electronic copy may be made for personal use only. Systematic reproduction and distribution, duplication of any material in this paper for a fee or for commercial purposes, or modification of the content of the paper are prohibited.

Nazanin Farjam, Reza Mehrabi, Haluk Karaca, Reza Mirzaeifar, and Mohammad Elahinia, "Modeling of NiTiHf using finite difference method," Proc. SPIE 10596, Behavior and Mechanics of Multifunctional Materials and Composites XII, 1059613 (March 27, 2018). DOI: https://doi.org/10.1117/12.2300857

The copyright holder has granted the permission for posting the article here. 


\section{Modeling of NiTiHf using finite difference method}

Nazanin Farjam, Reza Mehrabi, Haluk Karaca, Reza Mirzaeifar, Mohammad Elahinia

Nazanin Farjam, Reza Mehrabi, Haluk Karaca, Reza Mirzaeifar, Mohammad Elahinia, "Modeling of NiTiHf using finite difference method," Proc. SPIE 10596, Behavior and Mechanics of Multifunctional Materials and Composites XII, 1059613 (27 March 2018); doi: 10.1117/12.2300857 Health Monitoring, 2018, Denver, Colorado, United States 


\title{
Modeling of NiTiHf using Finite Difference Method
}

\author{
Nazanin Farjam ${ }^{\mathrm{a}}$, Reza Mehrabi ${ }^{\mathrm{a}}$, Haluk Karaca ${ }^{\mathrm{b}}$, Reza Mirzaeifar ${ }^{\mathrm{c}}$, Mohammad Elahinia*a \\ ${ }^{a}$ Mechanical, Industrial and Manufacturing Engineering (MIME) Department, University of \\ Toledo, Toledo, OH USA 43606; ${ }^{b}$ Dept. of Mechanical Engineering, University of Kentucky, \\ Lexington, KY USA 40506; ${ }^{\circ}$ Dept. of Mechanical Engineering, Virginia Tech, Blacksburg, VA \\ USA 24061.
}

\begin{abstract}
NiTiHf is a high temperature and high strength shape memory alloy with transformation temperatures above $100^{\circ} \mathrm{C}$. A constitutive model based on Gibbs free energy is developed to predict the behavior of this material. Two different irrecoverable strains including transformation induced plastic strain (TRIP) and viscoplastic strain (VP) are considered when using high temperature shape memory alloys (HTSMAs). The first one happens during transformation at high levels of stress and the second one is related to the creep which is rate-dependent. The developed model is implemented for NiTiHf under uniaxial loading. Finite difference method is utilized to solve the proposed equations. The material parameters in the equations are calibrated from experimental data. Simulation results are captured to investigate the superelastic behavior of NiTiHf. The extracted results are compared with experimental tests of isobaric heating and cooling at different levels of stress and also superelastic tests at different levels of temperature. More results are generated to investigate the capability of the proposed model in the prediction of the irrecoverable strain after full transformation in HTSMAs.
\end{abstract}

Keywords: High temeperature shape memory alloys, NiTiHf, uniaxial loading, analytical solution, finite difference method

\section{INTRODUCTION}

NiTi, as the most well-known Shape memory alloy (SMA) shows two distinct behaviors: superelastic (SE) and shape memory effect (SME). These behaviors are due to the phase transformation that happens in the material between martensite and austenite, which have different lattice structures. The material shows SE when it is in the austenite phase. At this region, the material can recover up to $8 \%$ of stress-induced strain. However, SME occurs when the material is in the martensite region, where stress-induced strain is recovered by heating the material up to the austenite phase. NiTi has received more attraction because of its ductility, compatibility, and stability which results in their application in biomedical devices and actuators ${ }^{1}$.

The transformation temperatures of NiTi are in the order of room temperature which limits their application in industries like automotive and aerospace, where the operating temperatures are in the order of $100^{\circ} \mathrm{C}$ or more. Researchers have solved this problem by adding a third element to NiTi-based SMAs like Palladium (Pd), Hafnium (Hf) and Zirconium (Zr), and the resultant material is called "high temperature shape memory alloy (HTSMA)",2, ${ }^{3}$. This third element can increase the transformation temperatures of the material significantly, and make them applicable to high temperature applications like aerospace and energy exploration industries ${ }^{4}$. Comparing these third elements, $\mathrm{Hf}$ and $\mathrm{Zr}$ are less expensive and less amount is needed to increase the transformation temperatures sufficiently. Furthermore, NiTiHf and NiTiZr are not exposed to creep, which is a problem with using the materials at high temperatures, since creep is activated when the temperature of the material is 0.3-0.4 melting temperature, and melting temperature of NiTiHf and NiTiZr are very high compared to their transformation temperatures ${ }^{5}$. Bigelow et al. ${ }^{6}$ have studied Ni-rich NiTiHf and showed that this alloy is very stable and superelastic at high temperatures. Exposing to the high temperatures, two more strains occur in SMAs; one is a viscoplastic strain which is related to creep, and the other is transformation-induced plastic (TRIP) strain which is related to the phase transformation.

*mohammad.elahinia@utoledo.edu; phone 1419 530-8224; fax 1419 530-8206; http://www.eng.utoledo.edu/ melahini/

Behavior and Mechanics of Multifunctional Materials and Composites XII,

edited by Hani E. Naguib, Proc. of SPIE Vol. 10596, 1059613 - (c) 2018 SPIE

CCC code: $0277-786 \mathrm{X} / 18 / \$ 18 \cdot$ doi: $10.1117 / 12.2300857$

Proc. of SPIE Vol. 10596 1059613-1 
Karaca et al. ${ }^{7}$ investigated the superelastic behavior of single crystal NiTiHf, as well as thermal cyclic tests and they showed a good superelasticity for this material under temperatures up to $200^{\circ} \mathrm{C}$. Different phenomenological modeling works have been done on SMAs, which are based on the continuum thermodynamics principles ${ }^{8-12}$. Lagoudas and Entchev ${ }^{13}$ entered the transformation-induced plasticity (TRIP) into their model for SMAs at high levels of stress. This model is also improved for HTSMAs by entering viscoplastic strain to the equations. The material that they used was NiTiPd which is sensitive to creep at high temperatures. Finite element method (FEM) is conducted with most of these modeling works.

In this study we present a semi-analytical approach, based on Gibbs free energy, to model the mechanical behavior of NiTiHf under uniaxial loading. For solving the equations finite difference method (FDM) is utilized, which is simpler in implementation and numerically less expensive, comparing to FEM. This method has been done for SMAs by Mirzaeifar et al. ${ }^{8}$ and Andani et al. ${ }^{14}$. Here, it is improved for HTSMAs and then applied to NiTiHf under uniaxial loading. The model is also verified with experimental data and a good agreement is observed. Using this model, the plastic strain, which remains as the residual strain in the material is predictable.

\section{GOVERNING EQUATIONS}

\subsection{General constitutive model}

The model is based on the Gibbs free energy and it is implemented by Boyd and Lagoudas ${ }^{10}$, and Qidwai and Lagoudas ${ }^{15}$. For HTSMAs, as explained above, two more strain terms are added: viscoplastic strain and transformation-induced plastic strain.

$$
\begin{aligned}
G\left(\sigma, \varepsilon^{t}, \varepsilon^{t p}, \varepsilon^{v p},\right. & T, \xi, p) \\
& =\frac{-1}{2 \rho} \sigma: S: \sigma-\frac{1}{\rho} \sigma:\left[\alpha:\left(T-T_{0}\right)+\varepsilon^{t}+\varepsilon^{t p}+\varepsilon^{v p}\right]+c\left[\left(T-T_{0}\right)-T \ln \left(\frac{T}{T_{0}}\right)\right]-s_{0} T \\
& +u_{0}+\frac{1}{\rho}\left[g^{t}(\xi)+g^{v p}(T, p)\right]
\end{aligned}
$$

Where $\rho, \mathrm{S}, \alpha, \mathrm{c}, s_{0}, u_{0}, \sigma, \varepsilon^{t}, \varepsilon^{t p}, \varepsilon^{v p}, T, \xi, \mathrm{p}, g^{t}$ and $g^{v p}$ are material mass density, effective compliance tensor, thermal expansion coefficient, specific heat, specific entropy, specific internal energy in the initial state, stress, transformation-induced strain, transformation-induced plastic strain, viscoplastic strain, temperature, martensitic volume fraction, effective viscoplastic strain, transformation and viscoplastic hardening functions, respectively ${ }^{16}$. The total strain can be defined as:

$$
\epsilon^{\text {total }}=-\rho \frac{\partial G}{\partial \sigma}=S: \sigma+\alpha:\left(T-T_{0}\right)+\varepsilon^{t}+\varepsilon^{t p}+\varepsilon^{v p}
$$

Where

$$
\dot{\varepsilon}_{t}=\Lambda^{t} \dot{\xi}, \quad \dot{\varepsilon}_{t p}=\Lambda^{t p} \dot{\xi}, \quad \dot{\varepsilon}_{v p}=\Lambda^{v p} \dot{p}
$$

$\Lambda^{t}, \Lambda^{t p}, \Lambda^{v p}$ and $\dot{p}$, the rate of viscoplastic strain, are expressed as:

$$
\Lambda^{t}=\left\{\begin{array}{l}
\frac{3}{2} H \frac{\dot{\sigma}}{\bar{\sigma}}(\dot{\xi}>0) \\
\frac{\varepsilon^{t-r}}{\xi^{t-r}}(\dot{\xi}<0)
\end{array}, \Lambda^{t p}=\left\{\begin{array}{c}
f^{t p}(\sigma) \Lambda^{v p}(\dot{\xi}>0) \\
-f^{t p}(\sigma) \Lambda^{v p}(\dot{\xi}<0)
\end{array}, \quad \Lambda^{v p}=\frac{3}{2} \frac{\dot{\sigma}}{\bar{\sigma}}, \dot{p}=\exp \left(\frac{-Q}{R T}\right) \bar{\sigma}^{N_{a}}\right.\right.
$$


$\mathrm{H}, \dot{\sigma}, \bar{\sigma}, \varepsilon^{t-r}, \xi^{t-r}, f^{t p}, \mathrm{Q}, \mathrm{R}$, and $\mathrm{N}_{\mathrm{a}}$ are the maximum recoverable strain, deviatoric part of the stress tensor, the effective stress, transformation strain at the reversal, martensitic volume fraction at the reversal, the TRIP strain generation rate at a given stress and three material constants, respectively. The Clausius-Durham inequality is defined as ${ }^{17}$ :

$$
\begin{gathered}
{\left[\sigma:\left(\Lambda^{t}+\Lambda^{t p}\right)-\rho \frac{\partial G}{\partial \xi}-g^{t}(\xi)\right] \dot{\xi}=\pi^{t} \dot{\xi}>0 \quad \forall \dot{\xi} \neq 0} \\
{\left[\sigma: \Lambda^{v p}-f^{v p}(p, T)\right] \dot{p}=\pi^{v p} \dot{p}>0 \quad \forall \dot{p}>0}
\end{gathered}
$$

$\pi^{t}$ and $\pi^{v p}$ are thermodynamic forces, and transformation and viscoplastic hardening functions are defined as:

$$
\begin{gathered}
g^{t}=\left\{\begin{array}{cc}
\frac{1}{2} \rho b^{M} \xi^{2}+\left(\mu_{1}+\mu_{2}\right) \xi & \dot{\xi}>0 \\
\frac{1}{2} \rho b^{A} \xi^{2}+\left(\mu_{1}-\mu_{2}\right) \xi & \dot{\xi}<0
\end{array}\right. \\
g^{v p}=\dot{p} f^{v p}(p, T)
\end{gathered}
$$

$\rho b^{M}, \rho b^{A}, \mu_{1}$ and $\mu_{2}$ are material constants. The transformation function showing the state of the material is expressed as ${ }^{8}$.:

$$
\phi^{t}= \begin{cases}\pi^{t}-Y^{t}=0 & \dot{\xi}>0 \\ -\pi^{t}-Y^{t}=0 & \dot{\xi}<0 \\ <0 & \dot{\xi}=0\end{cases}
$$

$Y^{t}$ is a threshold value for the thermodynamic force. The transformation function $\left(\phi^{t}\right)$ shows the state of the phase transformation; when the material is not during phase transformation, the value of the transformation function is less than zero. When the material is in forward $(\dot{\xi}>0)$ or reverse transformation $(\dot{\xi}<0)$, the value is zero ${ }^{8}$.

\subsection{Relations for uniaxial loading}

For the case of uniaxial loading, the explicit expression for martensitic volume fraction in forward and reverse transformation can be obtained as:

$$
\begin{aligned}
& \xi^{f w d}=\frac{1}{\rho b^{M}}\left[\left(H+f^{t p}(\sigma)\right) \sigma_{z}+\frac{1}{2} \sigma_{z}^{2} \Delta S_{33}+\rho \Delta c\left[\left(T-T_{0}\right)-T \ln \left(\frac{T}{T_{0}}\right)\right]+\rho \Delta s_{0}\left(T-M_{s}\right)\right] \\
& \xi^{r e v}=\frac{1}{\rho b^{A}}\left[\frac{\sigma_{z} \epsilon_{z z}^{t-r}}{\xi^{t-r}}+f^{t p}(\sigma) \sigma_{z}+\frac{1}{2} \sigma_{z}^{2} \Delta S_{33}+\rho \Delta c\left[\left(T-T_{0}\right)-T \ln \left(\frac{T}{T_{0}}\right)\right]+\rho \Delta s_{0}\left(T-A_{f}\right)\right]
\end{aligned}
$$

$\Delta$ (variable) shows the difference between martensite and austenite values of the variables. The material parameters in the equations above are:

$\mu_{1}=\frac{1}{2} \rho \Delta s_{0}\left(M_{s}+A_{f}\right)-\rho \Delta u_{0}, \mu_{1}=\frac{1}{2}\left(\rho b^{A}-\rho b^{M}\right)$,

$\rho b^{A}=-\rho \Delta s_{0}\left(A_{f}-A_{s}\right), \rho b^{M}=-\rho \Delta s_{0}\left(M_{s}-M_{f}\right), Y^{t}=-\frac{1}{2} \rho \Delta s_{0}\left(A_{f}-M_{s}\right)$

Using equations (10), (11), (2) and (3), the uniaxial strain for forward and reverse transformation is obtained: 


$$
\begin{gathered}
\epsilon_{z}^{f w d}=\frac{1}{\mathrm{E}_{A}+\xi^{f w d}\left(E_{M}-E_{A}\right)} \sigma_{z}+\left(H+f^{t p}(\sigma)\right) \xi^{f w d}+\alpha\left(T-T_{0}\right)+\exp \left(\frac{-Q}{R T}\right) \sigma_{z}^{N_{a}} \\
\epsilon_{z}^{r e v}=\frac{1}{E_{A}+\xi^{r e v}\left(E_{M}-E_{A}\right)} \sigma_{z}+\frac{\epsilon_{z}^{t-r}}{\xi^{t-r}} \xi^{r e v}+f^{t p}(\sigma) \xi^{r e v}+\alpha\left(T-T_{0}\right)+\exp \left(\frac{-Q}{R T}\right) \sigma^{N_{a}}
\end{gathered}
$$

As discussed in the introduction section, creep is negligible for NiTiHf at the temperatures and stresses of operation, due to the fact that the operation temperature of this material is less than 0.35 melting temperature, where creep comes into play. Therefore, viscoplastic strain term can be considered as zero.

\section{SOLUTION METHOD}

To solve the obtained equations, an iterative solution is considered. Finite difference method (FDM) as a MATLAB code is employed which has some benefits to the FEM, as mentioned above. The circular cross section is divided into $\mathrm{N}$ annular elements, as shown in Figure1, and for each element the stress or temperature is calculated based on the implemented equations. The input is strain which is applied to the material in M steps. Therefore, the axial and torsional strains for each element are obtained:

$$
\epsilon_{z}=\frac{\text { axial displacement }}{\text { length of the sample } * \text { total number of steps }} * \text { number of current step }
$$

\section{RESULTS}

The capability of the model is verified by the experimental results reported by the third author ${ }^{7}$ for uniaxial loading condition. The samples used for these experiments were cubes $4 * 4 * 8 \mathrm{~mm}$ under uniaxial compression, and the composition was $\mathrm{Ni}_{50.3} \mathrm{Ti}_{29.7} \mathrm{Hf}_{20}$ with $\left[\begin{array}{lll}1 & 1 & 1\end{array}\right]$ orientation. The superelastic and thermal cyclic behaviors of the material are considered to be isothermal and isobaric, respectively. Therefore, since the strain is uniform along the cross section, it is possible to use the model for rectangular samples, as well. Table 2 describes the material properties of the tested samples. $\mathrm{H}$ and $\mathrm{f}^{\mathrm{p}}$ are the maximum transformation strain after accounting for elastic moduli and the irrecoverable strain, respectively, and they are found from the cyclic heating and cooling tests. $\mathrm{E}_{\mathrm{A}}$ and $\mathrm{E}_{\mathrm{M}}$ are the austenite and martensite elastic modulus, respectively, and they are obtained from the stress-strain curves at the austenite and martensite phases (the slope of the plot at each region). $\mathrm{C}_{\mathrm{M}}$ and $\mathrm{C}_{\mathrm{A}}$ are calibrated from the phase diagram of the material.

Two different sets of results are investigated for validation: isobaric thermally cyclic behavior and isothermal superelastic behavior. Figure 1 and 2 are isobaric cooling and heating results at 100 and $1000 \mathrm{MPa}$, respectively. As reported in the experimental work ${ }^{7}$, the irrecoverable strain is negligible for the stress levels less than $700 \mathrm{MPa}$. Figure 3 and 4 show the superelastic behavior of NiTiHf at different temperatures of $180^{\circ} \mathrm{C}$ and $200^{\circ} \mathrm{C}$, respectively. The difference between model and experimental results is mostly due to the approximation of $f^{t p}$ function, because of the few number of experimental results for curve fitting. In our future work, we plan to do more experimental tests of isobaric thermal cycling to present a more accurate function. Superelastic behavior at different temperatures are modeled to show the effect of temperature for the same amount of transformation (Figure 5). It is obvious that increasing the temperature, the material goes through higher levels of stress which results in more transformationinduced plasticity which remains as a plastic strain after unloading. 


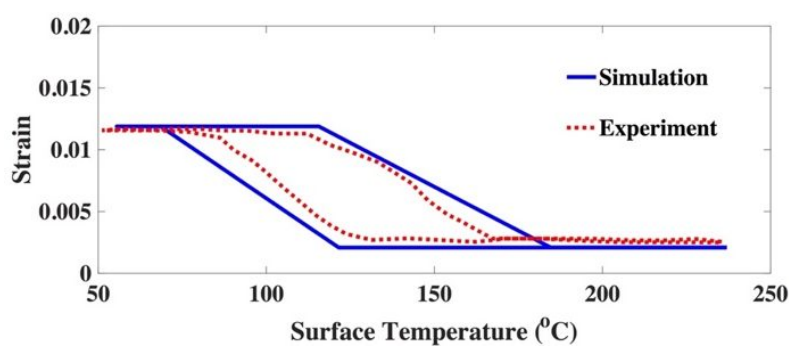

Figure 1. Thermal cyclic behavior under constant stress $=100 \mathrm{MPa}$

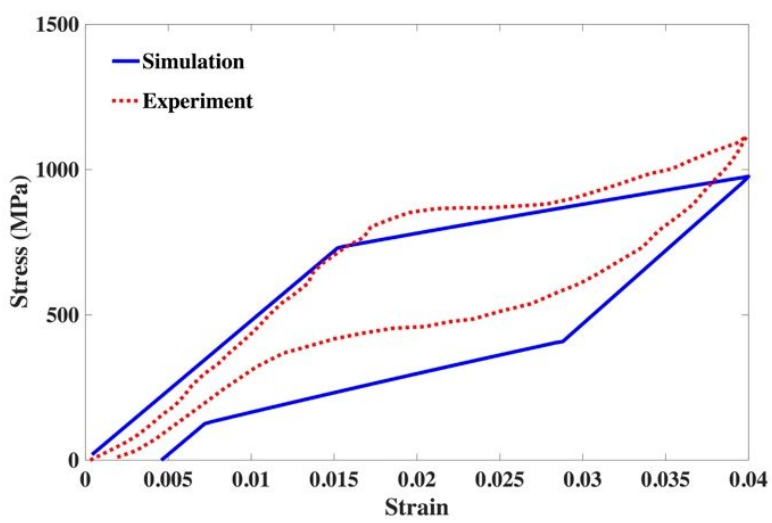

Figure 3. Superelastic behavior of NiTiHf at temperature $=180^{\circ} \mathrm{C}$

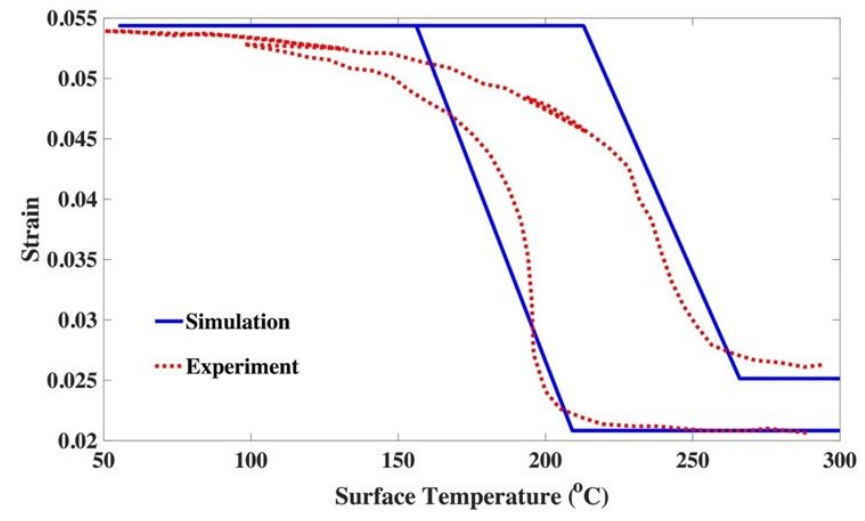

Figure 2. Thermal cyclic behavior under constant stress $=1000 \mathrm{MPa}$

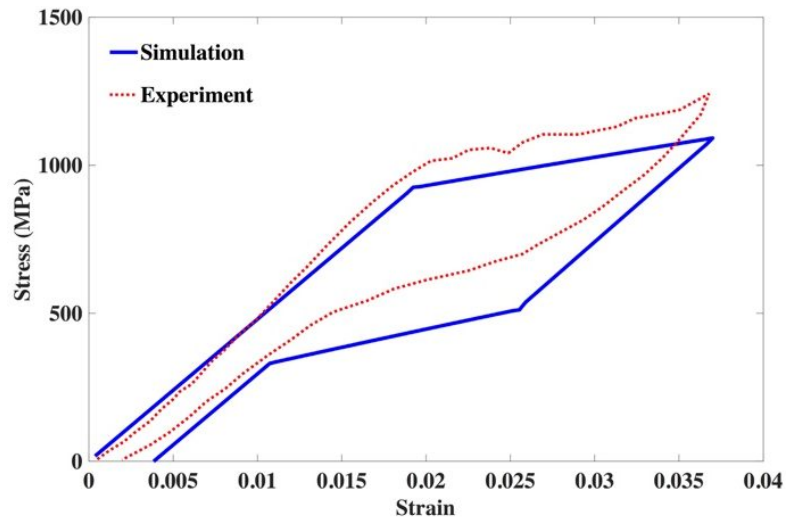

Figure 4. Superelastic behavior of NiTiHf at temperature $=200^{\circ} \mathrm{C}$

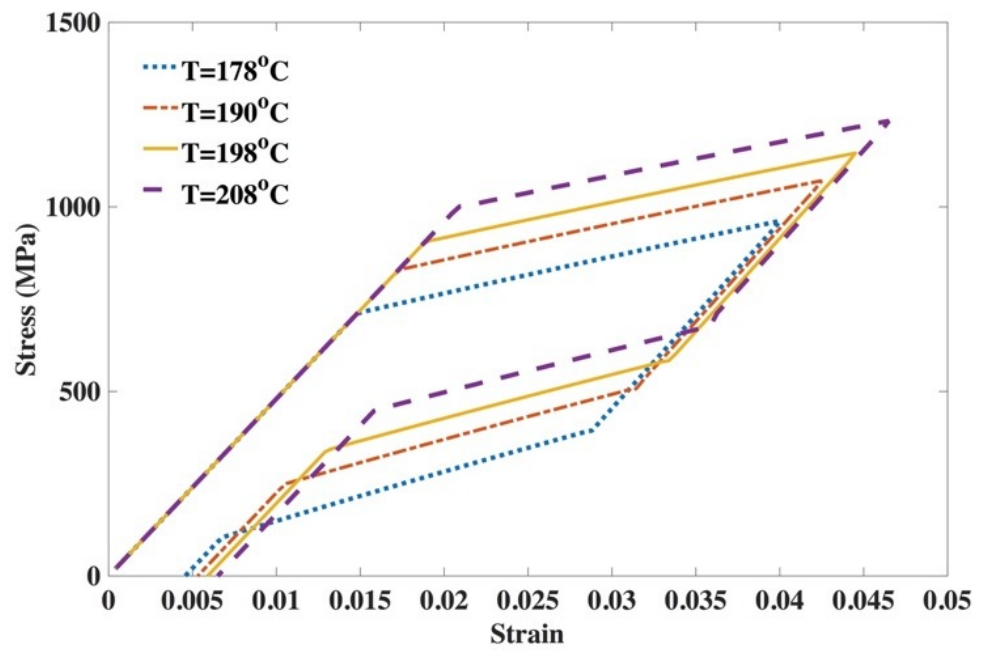

Figure 5. Superelastic behavior of NiTiHf at different temperatures for the same amount of transformation 


\section{CONCLUSION}

A semi-analytical model is improved to simulate the superelastic and thermal cyclic behavior of HTSMAs. Transformation-induced plastic strain and viscoplastic strain enters the equations, due to high stress levels, when operating at high temperatures. The solution method utilized to solve the equations is finite difference method. The results are compared with the experimental data on NiTiHf samples under uniaxial loading. Using this model, the residual strain in NiTiHf is predictable at different levels of temperatures.

\section{REFERENCES}

[1] M. Elahinia, [Shape memory alloy actuators: design, fabrication and experimental evaluation] John Wiley \& Sons, (2015).

[2] J. H. Mulder, [Investigation of High Temperature Shape Memory Alloys from the Ni-Ti-Zr and Ni-Ti-Hf Systems] Univ. Twente, (1995).

[3] D. N. AbuJudora, P. E. Thoma, M. Y. Kao et al., [High transformation shape memory alloy], US(1992).

[4] J. Ma, I. Karaman, and R. D. Noebe, "High temperature shape memory alloys," International Materials Reviews, 55(5), 257-315 (2010).

[5] C. M. Denowh, and D. A. Miller, "Thermomechanical training and characterization of Ni-Ti-Hf and NiTi-Hf-Cu high temperature shape memory alloys," Smart Materials and Structures, 21(6), (2012).

[6] G. S. Bigelow, A. Garg, I. I. Padula et al., "Load-biased shape-memory and superelastic properties of a precipitation strengthened high-temperature Ni50.3Ti29.7Hf20 alloy," Scripta Materialia, 64(8), 725-728 (2011).

[7] H. E. Karaca, S. M. Saghaian, B. Basaran et al., "Compressive response of nickel-rich NiTiHf hightemperature shape memory single crystals along the [111] orientation," Scripta Materialia, 65(7), 577-580 (2011).

[8] R. Mirzaeifar, R. DesRoches, and A. Yavari, "Analysis of the rate-dependent coupled thermo-mechanical response of shape memory alloy bars and wires in tension," Continuum Mechanics and Thermodynamics, 23(4), 363-385 (2011).

[9] L. C. Brinson, "One-dimensional constitutive behavior of shape memory alloys: thermomechanical derivation with non-constant material functions and redefined martensite internal variable," Journal of Intelligent Material Systems and Structures 4(2), 229-242 (1993).

[10] J. G. Boyd, and D. C. Lagoudas, "A thermodynamical constitutive model for shape memory materials. Part I. The monolithic shape memory alloy," International Journal of Plasticity, 12(6), 805-842 (1996).

[11] R. Mehrabi, M. Kadkhodaei, M. T. Andani et al., "Microplane modeling of shape memory alloy tubes under tension, torsion, and proportional tension-torsion loading," Journal of Intelligent Material Systems and Structures, 26(2), 144-155 (2015).

[12] R. Mehrabi, M. Kadkhodaei, and M. Elahinia, "A thermodynamically-consistent microplane model for shape memory alloys," International Journal of Solids and Structures, 51(14), 2666-2675 (2014).

[13] D. C. Lagoudas, and P. B. Entchev, "Modeling of transformation-induced plasticity and its effect on the behavior of porous shape memory alloys. Part I: constitutive model for fully dense SMAs," Mechanics of Materials, 36(9), 865-892 (2004).

[14] M. T. Andani, A. Alipour, A. Eshghinejad et al., "Modifying the torque-angle behavior of rotary shape memory alloy actuators through axial loading: A semi-analytical study of combined tension-torsion behavior," Journal of Intelligent Material Systems and Structures, 24(12), 1524-1535 (2013).

[15] M. A. Qidwai, and D. C. Lagoudas, "Numerical implementation of a shape memory alloy thermomechanical constitutive model using return mapping algorithms," International Journal for Numerical Methods in Engineering, 47(6), 1123-1168 (2000).

[16] D. J. Hartl, G. Chatzigeorgiou, and D. C. Lagoudas, "Three-dimensional modeling and numerical analysis of rate-dependent irrecoverable deformation in shape memory alloys," International Journal of Plasticity, 26(10), 1485-1507 (2010).

[17] L. Anand, and M. E. Gurtin, "Thermal effects in the superelasticity of crystalline shape-memory materials," Journal of the Mechanics and Physics of Solids 51, 1015-1058 (2003). 